\title{
Hard Science from Hard Materials
}

Okay, it's time for a break from politics, funding, visas, and "issues" in general. This letter is about science, all science, nothing but science. I would like to take the opportunity to simply call attention to four recent, remarkable papers. They have only two things in common. First, they came to my attention through random browsing during a single three-hour Amtrak ride (as opposed to a literature search). Second, they report dramatic observations and achievements on prototypical, almost old-fashioned materials. With all the attention devoted lately to fancy "bio" materials and infinitesimal "nano" objects, I found it refreshing to read of major advances in some of the bread-and-butter materials of our field.

The first article ${ }^{1}$ describes the activity of a finely dispersed silicate clay in controlling the phase and enhancing the mechanical strength of poly(vinylidene fluoride). This polymer is useful both for bulk engineering applications and also as a piezo/pyroelectric. When the clay is in the form of small enough platelets, it induces a preference for the otherwise less stable $\beta$ phase of the polymer at the expense of the $\alpha$ phase, and simultaneously produces order-of-magnitude increases in toughness, with stiffness also increasing, a very unusual occurrence. The role of the clay is as much to change the domain structure and energy dissipation mechanism of the polymer as it is to add a theoretically "less deformable" component. While most of the paper deals with the properties of the polymer, it struck me that such profound effects were due to a "lowly" clay.

The next article ${ }^{2}$ concerns strontium titanate $\left(\mathrm{SrTiO}_{3}\right)$. Mobile charge carriers can be introduced into this material through the omission of some of the oxygen from the ideal stoichiometric formula. The oxygen vacancies act as dopants, much as do impurity atoms in semiconducting silicon. The amazing thing about the present study is not the nonstoichiometric composition, but rather the atomicscale definition of the position of the vacancies and, furthermore, the ability to image these vacancies with a resolution of just a few unit cells in the interior of the sample. The imaging depends on observing strain fields that distort adjacent cation sites. Fascinating and techno-

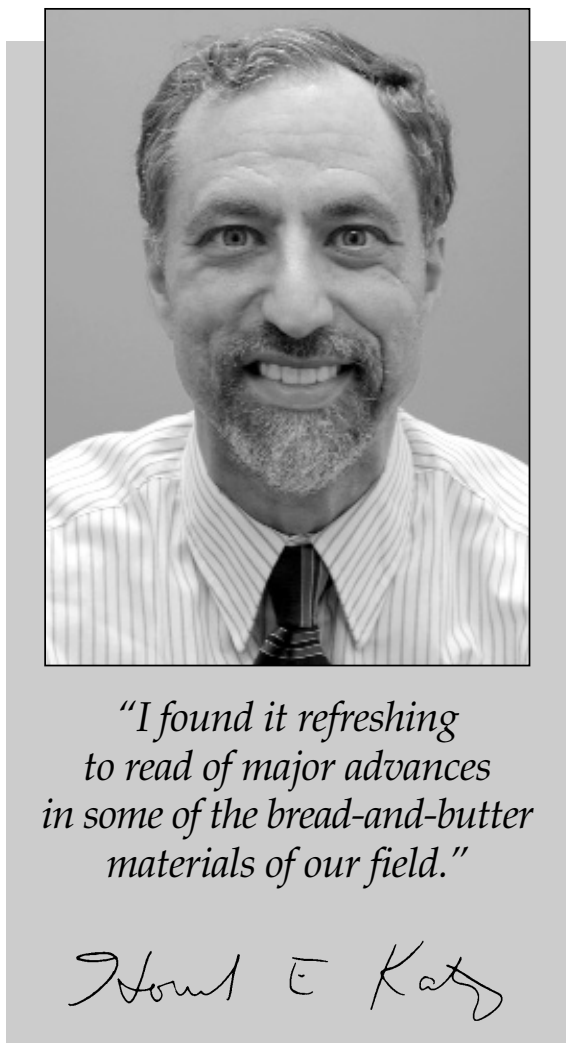

logically relevant questions can be addressed with this newly available capability: How far do vacancies migrate, to what extent do they associate, and what are the thermodynamic limits to their distributional possibilities? It is difficult enough to find individual heavy atoms on a surface; here, the observation is that of missing light atoms in the bulk. We thus come closer to defining oxide physics with the precision of conventional semiconductor physics.

The third article ${ }^{3}$ reports the realization of a holy grail in the field of oxide glasses. Aluminum oxide, certainly an ancient material, has long been attractive as a potential high-volume fraction component of glass because of anticipated improvements in mechanical properties, but it is thermodynamically unstable as a glass with respect to the crystalline phase, even when alloyed with other oxides. Even kinetic stabilization is problematic. The researchers in this article utilized a unique temperature/cooling rate window that produced $100-\mu \mathrm{m}$-diameter glassy beads consisting of up to about $80 \%$ alumina mixed with rare-earth and other oxides. The beads could then be sintered to form bulk transparent glasses and ceramics. The method enables the ultimate production of a wide variety of high-optical-quality oxide glasses, potentially revolutionizing this material class.

The final article ${ }^{4}$ in this miniseries focuses on another long-studied material, silicon carbide ( $\mathrm{SiC})$, with tantalizing capabilities, were it not for the large density of dislocations in its crystal that prevents high-efficiency electronic performance. A new growth method is reported here that produces $\mathrm{SiC}$ nearly dislocationfree. It was noted by the authors that dislocations in conventional $\mathrm{SiC}$ originated in the seed crystal and propagated very differently depending on the face of the seed used to initiate the growth. By growing the crystals in multiple stages from alternate faces, defect propagation is dramatically reduced and perhaps could be eliminated altogether. The electronic properties are much improved as well, to the point that speculation about $\mathrm{SiC}$ for high-power, high-frequency, and hightemperature applications is now possible.

I recently participated in a workshop on the theme "Materials: Impossible." These four articles each describe an advance in materials science that could have qualified for this workshop until now. They are responses to the attitude of "they said it couldn't be done!" As a scientist who works predominantly in "soft" materials, I am impressed, and I hope we can all be inspired by these success stories.

HOWARD E. KATZ 2004 MRS President

\section{References}

1. D. Shah, P. Maiti, E. Gunn, D.F. Schmidt, D.D. Jiang, C.A. Batt, and E.P. Giannelis, Adv. Mater. 16 (14) (July 2004) p. 1173.

2. D.A. Muller, N. Nakagawa, A. Ohtomo, J.L. Grazul, and H.Y. Hwang, Nature 430 (August 5, 2004) p. 657.

3. A. Rosenflanz, M. Frey, B. Endres, T. Anderson, E. Richards, and C. Schardt, Nature 430 (August 12, 2004) p. 761.

4. D. Nakamura, I. Gunjishima, S. Yamaguchi, T. Ito, A. Okamoto, H. Kondo, S. Onda, and K. Takatori, Nature 430 (August 26, 2004) p. 1009. 